GRAVITY AND COMPARATIVE ADVANTAGE:

ESTIMATION OF TRADE ELASTICITIES FOR THE AGRICULTURAL SECTOR

\author{
Kari E.R. Heerman \\ Ian M. Sheldon \\ Working Paper 24772 \\ http://www.nber.org/papers/w24772 \\ NATIONAL BUREAU OF ECONOMIC RESEARCH \\ 1050 Massachusetts Avenue \\ Cambridge, MA 02138 \\ June 2018
}

Ian Sheldon acknowledges financial support from USDA/ERS Cooperative Agreement, 58-3000-3-0058, "Complementarities in Commodity and Environmental Goods Trade: Implications for Analysis of Food and Agricultural and Agricultural Trade Liberalization" The views expressed herein are those of the authors and do not necessarily reflect the views of the National Bureau of Economic Research.

NBER working papers are circulated for discussion and comment purposes. They have not been peer-reviewed or been subject to the review by the NBER Board of Directors that accompanies official NBER publications.

(C) 2018 by Kari E.R. Heerman and Ian M. Sheldon. All rights reserved. Short sections of text, not to exceed two paragraphs, may be quoted without explicit permission provided that full credit, including $(\odot)$ notice, is given to the source. 
Gravity and Comparative Advantage: Estimation of Trade Elasticities for the Agricultural Sector

Kari E.R. Heerman and Ian M. Sheldon

NBER Working Paper No. 24772

June 2018

JEL No. F11,F14,Q17

\begin{abstract}
In this paper, a structural gravity model is presented which features intra-sector heterogeneity in agricultural productivity systematically linked to land and climate characteristics. The "systematic heterogeneity" ( $\mathrm{SH})$ gravity model predicts that countries with similar land and climate characteristics tend to specialize in the same agricultural products. Agricultural trade flow elasticities then depend on comparative advantage, with larger-magnitude trade flow responses predicted among countries more likely to specialize in similar agricultural products and thus compete head-to-head in foreign markets. This is in contrast to standard log-linear gravity models, which impose a restrictive pattern of trade flow elasticities that depend only on absolute advantage in the agricultural sector. We also show how the SH gravity model can accommodate product-specific trade costs. This allows the model to analyze changes in the dispersion of trade costs across products. Such analysis cannot be carried out in a standard gravity model, in which trade costs are assumed constant. Our results confirm economically and statistically significant heterogeneity in the effects of the variables that typically proxy for trade costs in gravity models and demonstrate that the SH gravity model is able to overcome the limitations imposed by the restrictive pattern of elasticities in a standard gravity model.
\end{abstract}

Kari E.R. Heerman

1400 Independence Ave., SW, Mail Stop 1800

Washington, DC 20250

keheerman@ers.usda.gov

Ian M. Sheldon

Department of Agricultural, Environmental, and Dev

Ohio State University

Columbus, $\mathrm{OH} 43210$

sheldon.1@osu.edu 


\section{Gravity and Comparative Advantage: Estimation of Trade Elasticities for the Agricultural Sector}

\section{Introduction}

The gravity model is a workhorse of applied international trade analysis. However, standard gravity models derived from a structural relationship in the most common trade models impose a restrictive pattern on the elasticity of bilateral trade flows with respect to changes in trade costs, which Heerman, Arita and Gopinath (2015) refer to as the Independence of Irrelevant Exporters (IIE) property. In models that feature the IIE property, the magnitude of the response of a country's export flows to a competitor's trade costs depends only on its absolute advantage in agriculture, irrespective of whether the competitor is likely to specialize in similar agricultural products. This is a particularly strong assumption in agriculture, where fundamental characteristics of climate and geography have a strong influence on the specific set of products in which a country has comparative advantage and thus the set of countries against which it competes most intensely.

We present a structural gravity model, the systematic heterogeneity (SH) gravity model, which features intra-sector heterogeneity in productivity linked to land and climate characteristics. The model predicts that countries with similar land and climate characteristics will systematically tend to specialize in the same products. Trade flow elasticities then depend on comparative advantage, with larger-magnitude predicted trade flow responses among countries more likely to specialize in similar products and thus compete head-to-head in foreign markets. 
A no-less advantageous additional benefit of the $\mathrm{SH}$ gravity model is that it can accommodate product-specific trade costs. Transportation, marketing and other costs vary tremendously and systematically across agricultural products due to differences in perishability and policy treatment, among others. As such, the extent to which trade costs obscure comparative advantage varies within the sector.

More practically, there is great demand for applied analysis of the production and trade implications of changes in agricultural policy. Although the agricultural sector represents a small share of the global economy, it is often pivotal in international trade relations. In the context of international negotiations, agricultural policy issues are typically considered at the product level. The SH gravity model's ability to capture changes in the distribution of trade costs across products is thus a substantial asset.

The SH gravity model specifies the relationship between trade flows and trade costs as a random coefficients logit model (Berry, 1994 and Berry, Levinsohn and Pakes, 1995). Therefore, our empirical approach is similar to the "mixed CES" model introduced in Adao, Costinot and Donaldson (2017). This is more complex than the linear methods used to estimate the standard gravity model. However, it requires little additional data.

In the next section we elaborate on the features of the standard structural gravity model that impose restrictions on trade elasticities and the implications of those restrictions. Next we present the SH gravity model, describe our data and estimation technique, and carry out a test that finds that the IIE property does not hold in agricultural trade data. Finally, we present the results of our model and demonstrate its ability to overcome the restrictions of the standard gravity model. 


\section{Background}

Until recently, the conventional view in international economics was that the gravity equation lacked microeconomic foundations (Head and Mayer, 2014). However, it is now considered general enough to be applied beyond a sub-set of countries or sectors (Eaton and Kortum, 2002; Anderson and Wincoop, 2003; Arkolakis, Costinot, and Rodríguez-Clare, 2012), and that importer and exporter fixed effects can be used to account for the multilateral trade resistance terms derived from different theoretical models (Feenstra, 2004). In addition, evaluating a standard gravity equation on the basis of exports (imports) to (by) country $n$, at the firm/industry/sector-level as opposed to the economy-wide level using bilateral trade, has a clear analytical justification, drawing on a range of trade theories, e.g., Melitz (2003); Anderson and Wincoop (2004); Chaney (2008); Anderson and Yotov (2010a; 2010b; 2012); Costinot, Donaldson, and Komunjer (2012); and Costinot and Rodríguez-Clare (2014). As a result, robust estimation of firm/industry/sector-level gravity equations using export (import) data is now common in the agricultural economics literature, some recent applications including: Reimer and Li (2010) (crop trade); Jayasinghe, Beghin, and Moschini (2010) (US corn seed exports); Cardamone (2011) (fruit exports); Chevassus-Lozza and Latouche (2012) (French firms' agri-food exports); Xu (2015) (agricultural trade); and Dal Bianco et al. (2016) (wine exports).

An important characteristic of the range of structural gravity models is that the quantitative implications that can be drawn from them are very dependent upon a key parameter: the elasticity of trade with respect to trade frictions such as tariffs (Simonovska and Waugh, 2014). Arkolakis et al. (2012) argue that the elasticity of trade, denoted as $\varepsilon$, is one of two 
sufficient statistics necessary for calculating the welfare effects of trade, the other being the share of expenditure within a specific country on domestically produced goods denoted as $\lambda$. They show that the change in a country's real income, $\hat{W}=W^{\prime} / W$, resulting from say a reduction in trade costs can be calculated as $\hat{W}=\hat{\lambda}^{1 / \varepsilon}$, where $\hat{\lambda}=\lambda^{\prime} / \lambda$ is the change in the share of domestic expenditure on imports. Importantly, changes in welfare are independent of the class of trade model, i.e., the source of the gains from trade depends on the type of trade model being estimated, but the aggregate gains from trade do not. Arkolakis et al. (2012) show that the welfare formula can be derived from three different structures: an Armington model (see Anderson and Wincoop, 2003), a Ricardian model (see Eaton and Kortum, 2002), and a heterogeneous firms model (see Melitz, 2003), where the margin of adjustment occurs respectively through consumption, reallocation of labor across sectors, and reallocation across firms within sectors.

For this equivalence result to hold, Arkolakis et al. (2012) impose a key restriction on the partial elasticities: the import demand system is CES. Given the elasticities capture the percentage change in relative imports by country $n$ from country $i$ given a change in trade $\operatorname{costs} \tau_{n i}$, the CES assumption implies that: there is a symmetric impact on relative demand $X_{n i} / X_{n n}$ for imports by $n$ for all exporters $i \neq n$; and, any change in a third country's trade $\operatorname{costs} \tau_{n i}{ }^{\prime}$ has the same proportional impact on $X_{n i}$ and $X_{n n}$. In other words, changes in relative demand depend only on changes in trade $\operatorname{costs} \tau_{n i}$. Given this result, Arkolakis et al. (2012) show that these effects can be recovered from a simple logarithmic gravity equation, the estimated parameter for changes in trade costs being treated as an estimate of the trade 
elasticity $\varepsilon$, and the change in real income of country $n$ due to the trade shock being estimated as, $\hat{W}_{n}=\hat{\lambda}_{n}^{1 / \varepsilon}$, irrespective of the margin of adjustment.

Turning to trade in agricultural products, we argue that the CES assumption is overly restrictive, i.e., the elasticity of each exporter i's trade flows with respect to a given competitor's, $i^{\prime}$, trade flows is constant and directly proportional to the exporter's market share in $n$, irrespective of whether or not $i$ competes with $i^{\prime}$. As noted earlier, Heerman et al. (2015), refer to this restriction as the IIE property, i.e., changes in a third country's trade $\operatorname{costs} \tau_{n i}{ }^{\prime}$ are "irrelevant" to the ratio of any two competitors' market share in a given import market $n$. The results of Arkolakis et al. (2012) indicate that IIE is implicitly imposed in trade models such as Eaton and Kortum (2002), Melitz (2003) and Anderson and Wincoop (2003).

Heerman et al. (2015) argue that the IIE property is very unlikely to hold in the case of agricultural trade due to characteristics of natural endowments (land, soil, and climate) and production requirements being non-random drivers of comparative advantage within the agricultural sector. Consequently, econometric results assuming IIE will likely be imprecise, and any predictions about the effect of changes in trade costs on bilateral agricultural trade and production patterns, along with any estimated welfare effects, may be quite misleading. Likewise, Adao et al. (2017) weaken the IIE restriction in order to allow exporters that are similar in terms of defined characteristics such as GDP per capita, to be closer substitutes in international trade.

For example, suppose we consider the fact that the United States has recently chosen not to ratify the Trans-Pacific Partnership (TPP) free trade agreement (FTA), but that the remaining 11 countries have chosen to proceed with the FTA. An expected benefit of TPP 
for U.S. agricultural sector would have been increased access to the Japanese market (Burfisher et al., 2014), but as a result of its withdrawal, Japanese tariff reductions will only be offered to remaining member countries such as Australia, Canada and Malaysia. If the IIE property holds, the reduction in agricultural tariffs under TPP would imply that Japanese buyers substitute to Australian, Canadian and Malaysian products and away from its nonTPP trading partners such as the United States in a constant and direct proportion to their initial market shares. However, this makes little sense if we consider that Australia, Canada and the United States have similar land endowments and climate characteristics, and therefore systematically specialize in a similar set of agricultural products, which contrasts with Malaysia which has little available land and has a tropical climate. Consequently, one would expect that exclusion from TPP will result in the United States losing a proportionately larger market share in Japan relative to Australia and Canada than it will lose relative to Malaysia.

In the context of this paper, the focus is on an extension of Eaton and Kortum (2002). The latter assumes that comparative advantage within manufacturing is a function of a random productivity variable that is independently distributed across products in the sector. Specifically, no two countries are more likely to compete against each other exporting the same products than any other country, i.e., the IIE property is assumed to hold. Extensions of Eaton and Kortum (2002) to multisector analysis by, inter alia, Burstein and Vogel (2010), Chor (2010), Costinot et al. (2012), Shikher (2011, 2012), Caliendo and Parro (2015), Tombe (2015), and Kerr (2017) implicitly recognize the limitation of this assumption, allowing average productivity, and in some cases the dispersion of productivity to vary across sectors, generating non-random patterns of trade specialization across sectors and sub-sectors. 
However, these models still maintain the assumption of random heterogeneity within each sector or sub-sector, the IIE property holding at that level. In addition, there are practical limitations to a multi sub-sector approach within agriculture (Heerman, 2013). First, the researcher has to be able to define sub-sectors of like products such that specialization of a country within that sub-sector can be assumed to be randomly determined ex ante. For example, Reimer and Li (2010) focused on trade in crop agriculture, a well-defined subsector, but this still ignores the fact that agricultural product-specific farm and trade policies may be enough to distort any underlying forces of comparative advantage for crops that are substitutes in production. Second, disaggregation requires a dependent variable constructed from matching bilateral trade and production data for each subsector, and in the case of agriculture, where many products are thinly traded, zero trade flows can easily dominate available observations.

The key departure in this paper is the introduction of systematic heterogeneity into the agricultural sector. Specifically, the likelihood a country has a comparative advantage in a set of products depends not only on a randomly drawn technological productivity-augmenting parameter, but also a set of country and product-specific characteristics including land and climate. For example, agricultural R\&D in the United States might generate a diseaseresistant variety of bananas, but the land and climate requirements for growing bananas means the United States is unlikely to be a competitive exporter, and would therefore not be affected by any changes in the banana-importing regime of the European Union (EU). Alternatively, the United States has a technological advantage in producing geneticallymodified corn for which it also has the appropriate land and climate requirements, and it could face increased competition in the Mexican export market from close competitors like 
Brazil if market access for U.S. agriculture were to become more-costly as a result of the North American Free Trade Agreement (NAFTA) renegotiations. Fally and Sayre (2018) likewise allow heterogeneous natural resource productivity in commodities to influence comparative advantage. In contrast to our approach, which explicitly links a product's productivity in a common factor, viz., land, to country and product characteristics, in their model each commodity is produced with a specific natural resource.

Allowing for systematic heterogeneity also means that trade costs may vary across products and countries within sectors. This matters in agriculture where trade costs can differ significantly due to the intrinsic characteristics of products and/or the types of trade and other policies applied to those products. For example, compared to Brazil, the United States has very low trade costs of exporting corn and soybeans to Mexico, partly due to geographical proximity, but also because it has a very efficient storage and transportation system that minimizes the cost of spillage etc. So any increase in trade barriers to Mexican imports from the United States would be partially mitigated by the higher costs of importing more corn and soybeans from Brazil. Likewise, the costs of the United States exporting processed pork products to Mexico will have higher handling costs than corn due to the risks of perishability and the need for refrigerated transportation. Importantly, the relative difference between these advantages are not likely to be constant.

Trade policies also vary significantly across countries, with average MFN applied tariff rates in agriculture ranging from 1.2 percent in Australia, through 33.5 percent in India, to 66.7 percent in Egypt (Bagwell, Bown and Staiger, 2016). These average differences in tariffs can be captured in standard gravity models, but hide significant differences across products. 
Applied agricultural tariffs exhibit a good deal of heterogeneity across both products and countries. For example, Jales et al. (2005) report that developed countries typically have a number of very high agricultural tariffs and a large number of low tariffs, implying low mean tariffs with a high degree of tariff dispersion. By contrast, developing countries tend to have higher mean agricultural tariffs, and less tariff dispersion. In the case of tariff-rate quotas (TRQs), 1,400 have been introduced since 1995, with over-and in-quota tariffs averaging 123 and 63 percent respectively (Jales et al., 2005).

\section{The Model}

The SH gravity model environment is comprised of $I$ countries engaged in bilateral trade. Importers are indexed by $n$ and exporters by $i$. The agricultural sector consists of a continuum of products indexed by $j \in[0,1]$. To produce quantity $q_{i}(j)$ of product $j$ requires labor $\left(N_{i}\right)$, land $\left(L_{i}\right)$, and intermediate inputs $Q_{i}$ combined according to the function:

\section{Equation 1}

$$
q_{i}(j)=z_{i}(j)\left(N_{i}^{\beta}\left(a_{i}(j) L_{i}\right)^{1-\beta}\right)^{\alpha}{Q_{i}}^{1-\alpha}
$$

where $z_{i}(j)$ represents product $j$-specific technological productivity and $a_{i}(j)$ represents product $j$-specific land productivity. Technological productivity is modeled as an independently distributed Fréchet random variable with mean parameter $T_{i}$ and dispersion parameter $\theta$ as in Eaton and Kortum (2002). Exporters with high values of $T_{i}$ have a greater probability of a high realization of $z_{i}(j)$ for any given agricultural product. 
Product-specific land productivity, $a_{i}(j)$, reflects the suitability of exporter $i$ 's environment for product $j$. We assume $a_{i}(j)$ follows a parametric density that is a deterministic function of exporter i's agro-ecological characteristics and product $j$ 's production requirements. For example, countries with a climate like Ecuador will systematically tend to have higher values of $a_{i}(j)$ for $j=$ bananas.

Markets are perfectly competitive. The price offered by exporter $i$ for product $j$ in market $n$ is therefore equal to the unit cost of producing in country $i$ and marketing in country $n$. Exporters face additional costs, $\tau_{n i}(j)>1$ to sell product $j$ in import market $n$. Trade costs are assumed to take the iceberg form, with $\tau_{n n}(j)=1$ and $\tau_{n i}(j) \geq \tau_{n l}(j) \tau_{l i}(j)$. We assume $\tau_{n i}(j)$ follows a parametric density across products that is a deterministic function of product-specific policies and other marketing requirements. Productivity and trade cost distributions are assumed independent of each other.

Trade occurs as buyers in each import market seek out the lowest price offer for each product. Heerman (2013) shows that for an individual product, the probability exporter $i$ offers the lowest price in market $n$ is:

\section{Equation 2}

$$
\pi_{n i}(j)=\frac{T_{i}\left(\tilde{a}_{i}(j) c_{i} \tau_{n i}(j)\right)^{-\theta}}{\sum_{l=1}^{I} T_{l}\left(\tilde{a}_{l}(j) c_{l} \tau_{n l}(j)\right)^{-\theta}}
$$

Exporter $i$ 's total share of importer market $n$ agricultural expenditure is the unconditional probability it offers the lowest price for an agricultural product: 


\section{Equation 3}

$$
\operatorname{Pr}\left(p_{n i}(j)=p_{n}(j)\right) \equiv \pi_{n i}=\int \frac{T_{i}\left(\tilde{a}_{i} c_{i} \tau_{n i}\right)^{-\theta}}{\sum_{l=1}^{I} T_{l}\left(\tilde{a}_{l} c_{l} \tau_{n l}\right)^{-\theta}} d F_{a_{n}}(\widetilde{\boldsymbol{a}}) d F_{\tau_{n}}(\boldsymbol{\tau})
$$

where $\tilde{a}_{i}(j)=a_{i}(j)^{-\alpha^{A}\left(1-\beta^{A}\right)}, c_{i}$ is the cost of an input bundle, and $d F_{a_{n}}(\widetilde{\boldsymbol{a}}) d F_{\tau_{n}}^{A}(\boldsymbol{\tau})$ is the joint density of $\widetilde{\boldsymbol{a}}=\left[\widetilde{\boldsymbol{a}}_{1}, \ldots, \widetilde{\boldsymbol{a}}_{I}\right]$ and $\boldsymbol{\tau}^{A}=\left[\boldsymbol{\tau}_{n 1}^{A}, \ldots, \boldsymbol{\tau}_{I(I-1)}^{A}\right]$ over agricultural products consumed in import market $n$. Equation 3 is a gravity-like relationship between market share on the one hand and exporter characteristics and bilateral trade costs on the other. It is a weighted sum of $\pi_{n i}(j)$, where the weights reflect the importance of each product in market $n$ consumption.

An expression equivalent to Equation 3 can also be derived from a demand-side model, as in the structural gravity equation outlined in Anderson and van Wincoop (2003) and others. In that case $T_{i}$ is a share parameter that is an outcome of the Armington assumption and $-\theta=$ $1-\sigma$, where $\sigma$ is the elasticity of substitution (Anderson and Yotov, 2010a). In a demand side setting, the parameter $a_{i}(j)$ could be used to represent product-specific preferences linked to characteristics of product $j$ produced in country $i$. We leave the details of this extension for future work.

\section{Trade Elasticity}

Heerman et al. (2015) shows that in the SH gravity model, elasticity of market share with respect to a change in bilateral trade costs between exporter $i$ and the importing country $n$ can be written: 


\section{Equation 4}

$$
\frac{\partial \pi_{n i}}{\partial \tau_{n l}} \frac{\tau_{n l}}{\pi_{n i}}= \begin{cases}-\theta\left(\left(1-\pi_{n i}\right)-\frac{1}{\pi_{n i}} \operatorname{var}\left(\pi_{n i}(j)\right)\right) & l=i \\ \frac{\theta}{\pi_{n i}}\left(\operatorname{cov}\left(\pi_{n i}(j), \pi_{n l}(j)\right)+\pi_{n i} \times \pi_{n l}\right) & l \neq i\end{cases}
$$

Elasticities depend on cross-product differences in $\pi_{n i}(j)$, with $\operatorname{var}\left(\pi_{n i}(j)\right)$ and $\operatorname{cov}\left(\pi_{n i}(j), \pi_{n l}(j)\right)$ functions of the distributions of $a_{i}(j)$ and $\tau_{n i}(j)$. The direct effect of lower bilateral trade costs is decreasing in $\operatorname{var}\left(\pi_{n i}(j)\right)$. This implies that market share is less elastic for exporters that specialize in products for which competition is less intense, or for which trade costs remain high. The indirect effect of a change in a competitor's bilateral trade costs is increasing in $\operatorname{cov}\left(\pi_{n i}(j), \pi_{n l}(j)\right)$. The indirect elasticity will therefore be larger among competitors with similar distributions of $a_{i}(j)$, and further augmented when $\tau_{n i}(j)$ is also similar.

In a standard gravity model $\pi_{n i}(j)=\pi_{n i}$ : The probability of comparative advantage in an individual product does not depend on product or exporter characteristics. Every exporter is thus equally likely to offer the lowest price in every agricultural product and $\operatorname{var}\left(\pi_{n i}(j)\right)=$ $\operatorname{cov}\left(\pi_{n i}(j), \pi_{n l}(j)\right)=0$. Therefore, trade elasticities are a constant proportion of market share.

\section{Equation 5}

$$
\frac{\partial \pi_{n i}}{\partial \tau_{n l}} \frac{\tau_{n l}}{\pi_{n i}}=\left\{\begin{array}{cc}
-\theta\left(1-\pi_{n ;}\right) & l=i \\
\theta \pi_{n l} & l \neq i
\end{array}\right.
$$


These elasticities are a representation of the IIE property, which is imposed in every structural gravity model derived from a trade model that assumes a CES import demand system.

\section{Specification and Data}

We estimate parameters of the productivity and trade cost distributions for agriculture as in Heerman et al. (2015) by specifying Equation 3 as a random coefficients logit model. We begin as in Eaton and Kortum (2002) by defining $S_{i}=\ln \left(T_{i}\right)-\theta \ln \left(c_{i}\right)$. This is exporter $i$ 's average technological productivity adjusted for unit production costs.

\section{Land Productivity Distribution}

We specify $a_{i}(j)$ as a parametric function of exporter land and climate characteristics and product land and climate requirements:

\section{Equation 6}

$$
\ln \left(a_{i}(j)\right)=\boldsymbol{X}_{i} \boldsymbol{\delta}(j)=\boldsymbol{X}_{i} \boldsymbol{\delta}+\boldsymbol{X}_{i}(\boldsymbol{E}(j) \boldsymbol{\Lambda})^{\prime}+\boldsymbol{X}_{i}\left(v_{E}(j) \boldsymbol{\Sigma}_{E}\right)^{\prime}
$$

where $\boldsymbol{X}_{i}$ is a $1 \times k$ vector of variables describing country $i$ 's characteristics; $\boldsymbol{\delta}$ is a $k \times 1$ vector of coefficients; $\boldsymbol{E}(j)$ is a $1 \times m$ vector of product $j$-specific production requirements that can be observed and quantified; $\boldsymbol{\Lambda}$ is an $m \times k$ matrix of coefficients that describes how the relationship between elements of $\boldsymbol{X}_{i}$ and land productivity varies across products with $\boldsymbol{E}(j)$; and $\boldsymbol{v}_{E}(j)$ is a $1 \times k$ vector that captures the effect of unobservable product $j$-specific requirements with matrix $\boldsymbol{\Sigma}_{E}$.

We specify three types of exporter characteristics, climate, elevation and agricultural land: 


$$
\boldsymbol{X}_{i}=\left[\begin{array}{lllll}
a l_{i} & e l v_{i} & \operatorname{trp} & \operatorname{tmp}_{i} & \text { bor }_{i}
\end{array}\right]
$$

where $a l_{i}$ is the log of arable land per capita, $e l v_{i}$ is the share of rural land between 800 and 3000 meters above sea level, and the remaining elements are the shares of total land area in tropical, temperate, and boreal climate zones. The vector $j=\left[\begin{array}{lll}\boldsymbol{E}(j) & \boldsymbol{v}_{\boldsymbol{E}}(j)\end{array}\right]$ defines products in terms of their suitability for production under the conditions defined by $\boldsymbol{X}_{\boldsymbol{i}}$.

We define:

$$
\boldsymbol{E}(j)=\left[\begin{array}{lllll}
\operatorname{alw}(j) & \operatorname{elv}(j) & \operatorname{trp}(j) & \operatorname{tmp}(j) & \operatorname{bor}(j)
\end{array}\right]
$$

where $\operatorname{alw}(j)$ describes product- $j$ land requirements, $\operatorname{elv}(j)$ captures its elevation requirements, and $\operatorname{trp}(j), \operatorname{tmp}(j)$, and $\operatorname{bor}(j)$ describe climate requirements. These variables relate exporter $i$ 's characteristics to absolute advantage in agriculture through $\boldsymbol{X}_{i} \boldsymbol{\delta}$, and describe how they systematically influence the set of products within the agricultural sector in which it has comparative advantage through $\boldsymbol{X}_{i}(\boldsymbol{E}(j) \boldsymbol{\Lambda})^{\prime}$.

Note that we define the land intensity of product $j$ production using data on land per agricultural worker, whereas we use agricultural land per capita in $\boldsymbol{X}_{i}$. Elements of $\boldsymbol{X}_{\boldsymbol{i}}$ represent the factors that influence exporter $i$ 's potential comparative advantage, whereas elements of $\boldsymbol{E}(j)$ represent the ideal conditions under which product $j$ is produced.

\section{Trade Cost Distribution}

We specify product- $j$ trade costs as:

\section{Equation 7}

$$
\ln \left(\tau_{n i}(j)\right)=\boldsymbol{t}_{n i} \boldsymbol{\beta}(j)=\boldsymbol{t}_{n i} \boldsymbol{\beta}+e x_{i}+\boldsymbol{t}_{n i}\left(\boldsymbol{v}_{t_{n}}(j) \boldsymbol{\Sigma}_{t}\right)^{\prime}+\xi_{n i}
$$


where $\boldsymbol{t}_{n i}$ is a $1 \times m$ vector describing the relationship between exporter $i$ and import market $n, \boldsymbol{\beta}$ is an $m \times 1$ vector of parameters; $e x_{i}$ is an exporter-specific trade cost captured by a fixed effect as in Waugh (2010); $\boldsymbol{v}_{t_{n}}(j)$ is a $1 \times m$ vector that captures the effect of unobservable product $j$-specific trade costs with scaling matrix $\boldsymbol{\Sigma}_{t}$, and $\xi_{n i}$ captures unobservable or unquantifiable bilateral trade costs that are common across products and orthogonal to the regressors.

We define:

$$
\boldsymbol{t}_{n i}=\left[\begin{array}{llll}
b_{n i} & l_{n i} & r t a_{n i} & \boldsymbol{d}_{n i}
\end{array}\right]
$$

where $b_{n i}, l_{n i}$ and $r t a_{n i}$ equal one if the two countries share a common border or language or are members of a common regional free trade agreement. The $1 \times 6$ vector $\boldsymbol{d}_{n i}$ assigns each country pair to one of six distance categories as defined in Eaton and Kortum (Table 1).

\section{Table 1: Definition of distance variables}

\begin{tabular}{ll} 
Variable & Distance, miles \\
\hline Distance 1 & {$[0,375)$} \\
Distance 2 & {$[375,750)$} \\
Distance 3 & {$[750,1500)$} \\
Distance 4 & {$[1500,3000)$} \\
Distance 5 & {$[3000,6000)$} \\
Distance 6 & {$[6000$, maximum $]$} \\
\hline
\end{tabular}

\section{Estimating Productivity and Trade Cost Distribution Parameters}

Using our definitions of $a_{i}(j)$ and $\tau_{n i}(j)$ in Equation 3, we obtain a random coefficients logit model of agricultural market share: 


\section{Equation 8}

$$
\pi_{n i}=\int \frac{\exp \left\{S_{i}+\theta \alpha_{i}\left(1-\beta_{i}\right) \boldsymbol{X}_{i} \boldsymbol{\delta}(j)-\theta \boldsymbol{t}_{n i} \boldsymbol{\beta}(j)\right\}}{\sum_{l=1}^{I}\left\{S_{i}+\theta \alpha_{l}\left(1-\beta_{l}\right) \boldsymbol{X}_{l} \boldsymbol{\delta}(j)-\theta \boldsymbol{t}_{n l} \boldsymbol{\beta}(j)\right\}} d \widehat{F}_{E_{n}}(\boldsymbol{E}) d \hat{F} \boldsymbol{v}_{n}(\boldsymbol{v})
$$

where $d \hat{F}_{E_{n}}(\boldsymbol{E}) d \hat{F} \boldsymbol{v}_{n}(\boldsymbol{v})$ is the empirical density of products imported by market $n$ defined jointly by their land and climate characteristics, unobserved agro-ecological requirements and trade costs. We estimate Equation 8 using a simulated method of moments approach similar to that in Berry et al., (1995), which is detailed in Nevo (2000) and Train (2009). To evaluate the integral, we use the "smooth simulator" suggested by Nevo (2000):

\section{Equation 9}

$$
\hat{\pi}_{n i}=\frac{1}{n s} \sum_{j=1}^{\mathrm{ns}} \frac{\exp \left\{\tilde{S}_{i}+\theta \alpha_{i}\left(1-\beta_{i}\right) \boldsymbol{X}_{i} \boldsymbol{\delta}(j)-\theta \boldsymbol{t}_{n i} \boldsymbol{\beta}(j)\right\}}{\sum_{l=1}^{I}\left\{\tilde{S}_{i}+\theta \alpha_{l}\left(1-\beta_{l}\right) \boldsymbol{X}_{l} \boldsymbol{\delta}(j)-\theta \boldsymbol{t}_{n l} \boldsymbol{\beta}(j)\right\}}
$$

where $\tilde{S}_{i}=S_{i}+\theta \alpha_{i}\left(1-\beta_{i}\right) \boldsymbol{X}_{\boldsymbol{i}} \boldsymbol{\delta}$ is a country fixed effect. We use the minimum distance procedure suggested by Nevo (2000) to obtain $\hat{S}_{i}$ and $\boldsymbol{\delta}$ from $\hat{\tilde{S}}_{i}$.

\section{Data}

Parameters of the productivity and trade cost distributions are estimated using production and trade data from 2006. Bilateral market shares $\left(\pi_{n i}\right)$ are calculated by dividing bilateral import value by total domestic expenditure, calculated as the sum of production value and net exports. Domestic market share is calculated as $\pi_{n n}=1-\sum_{i \neq n} \pi_{n i}$. Our data consists of a sample of 63 countries and 134 agricultural items for which data on both bilateral trade and the gross value of production in U.S. dollars are available (FAO, 2013). These are mostly primary agricultural products. Elements of $\boldsymbol{t}_{n i}$ are obtained from the CEPII gravity data set 
(Head, Mayer and Ries, 2009). While land and climate requirements for each product are not directly observable to the economist, we do observe conditions of their production around the world.

We therefore use observable characteristics of exporting countries to construct "observable" product requirements matrix $\boldsymbol{E}(j)$ for each of the $J=134$ items for which the FAO publishes both production and trade data. This approach is valid under two assumptions: First, $\boldsymbol{E}(j)$ is distributed across products following the empirical distribution of requirements for agricultural products defined at the "item" level by the FAO. Second, exporting is positively correlated with high values of $a_{i}(j)$. We measure $\operatorname{elv}(j)$ and $\operatorname{alw}(j)$ as in Heerman et al. (2015) as the export-weighted average of exporters' share of land at high elevation $\left(e l v_{i}\right)$ and arable land per agricultural worker $\left(a l w_{i}\right)$ using data on arable land per agricultural worker from World Bank (2012) and elevation data from CIESIN (2010), respectively.

A drawback of defining product requirements as export-weighted averages of country characteristics is that it is not very precise. Many important agricultural exporters have varied terrain and climate within their borders. For example, roughly 20 percent of global wheat exports originated in Canada in 2006. However, while a large share of total Canadian land area is in the boreal climate zone, its wheat production is concentrated in temperate regions. A trade-weighted average of climate distributions thus misrepresents wheat's climate requirements.

We are able to improve on the measurement of product-specific climate requirements used in Heerman et al. (2015), taking advantage of information on product-specific production 
across climate zones within countries provided by the GTAP land use database (Lee et al., 2005). As part of an effort to model the impact of climate change on the agricultural sector, the database provides estimates of land rent for ten product categories in 18 agro-ecological zones (AEZs) within in each of several countries.

An AEZ is a defined zone based on soil, landform and climactic characteristics. A country's estimated land rent in AEZ $x$ for crop $y$ is calculated by by apportioning the crop's total land rent across AEZ's in proportion to its share in the value of crop y production. To calculate product climate requirements, we assign each of the crops in our data set to one of the ten GTAP aggregates. We then calculate the share of land rent in each zone and aggregate these shares into a distribution of land rent across tropical, temperate and boreal climate zones for each product, country pair. Finally, we define product $j$ climate requirements as the export-weighted average of these land rent distributions. The GTAP land use database does not calculate a distribution of land rent across climate zones for animal products. We use export-weighted averages of country climate distributions, as we did for land and elevation intensity, to calculate $[\operatorname{trp}(j) \operatorname{tmp}(j) \quad \operatorname{bor}(j)]$ for these products.

The $n s=900$ products used to evaluate Equation 9 for each importer and its trading partners are drawn from $d \widehat{F}_{E_{n}}(\boldsymbol{E}) d \hat{F} \boldsymbol{v}_{n}(\boldsymbol{v})$. We construct this density as in Heerman et al. (2015), first using FAO item level import data to estimate $d \widehat{F}_{E_{n}}(\boldsymbol{E})$, the empirical distribution of $\boldsymbol{E}(j)$ across products imported by each market by compiling a list of 1000 imported items defined by the vector $\boldsymbol{E}(j)$ for each market $n$. Unique values of $\boldsymbol{E}(j)$ are represented in $d \widehat{F}_{E_{n}}(\boldsymbol{E})$ in proportion to the associated FAO item's share in total imports. That is, if $15 \%$ of importer n's total agricultural imports are of the FAO item "wheat", then $E$ (wheat) makes 
up 150 entries on $d \hat{F}_{E_{n}}(\boldsymbol{E})$. Next we draw values of $\boldsymbol{E}(j)$ using uniform draws from each country's distribution. The distribution is completed by associating each item on the list

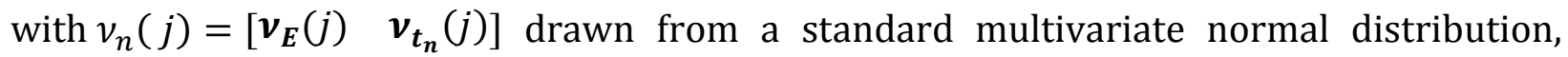
effectively generating a "data set" of 900 unique products imported by each market.

\section{A Test for the IIE Property}

If the IIE property holds in the data, the standard gravity model adequately captures trade elasticities and welfare can be calculated following the simple approach described in Arkolakis et al. (2012). That is, when all heterogeneity can be assumed independent, Equation 3 becomes:

\section{Equation 10}

$$
\operatorname{Pr}\left(p_{n i}(j)=p_{n}(j)\right) \equiv \pi_{n i}=\frac{T_{i}\left(c_{i} \tau_{n i}\right)^{-\theta}}{\sum_{l=1}^{I} T_{l}\left(c_{l} \tau_{n l}\right)^{-\theta}}
$$

The ratio $\pi_{n i} / \pi_{n n}$ can then be log-linearized, delivering a standard gravity model. Using the trade cost specification described above, this is:

\section{Equation 11}

$$
\ln \left(\frac{\pi_{n i}}{\pi_{n n}}\right)=S_{i}-S_{n}-\theta \alpha_{i}\left(1-\beta_{i}\right) \boldsymbol{X}_{i} \boldsymbol{\delta}-\theta \boldsymbol{t}_{n i} \boldsymbol{\beta}
$$

A test of whether the IIE property holds in the data is suggested by those developed for its demand-side parallel, the independence of irrelevant alternatives (IIA) (Greene 2003). McFadden and Train (2000) describe a test that can be used to evaluate whether IIE holds in our agricultural trade data. The idea behind this test is that if all heterogeneity in price offers 
is independently distributed, market shares should be uncorrelated across exporters and deviations from average trade costs will not have a statistically significant impact on bilateral market share. The formal hypothesis is that market share can be represented by Equation 10 against the alternative that comparative advantage is not independently distributed across products.

To conduct the test, parameter estimates from Equation 11 are used to calculate estimated market shares $\hat{\pi}_{n i}$. These estimates are then used to construct artificial variables, which take the form:

$$
z_{n i}=\frac{1}{2}\left(t_{n i}-t_{n}\right)^{2}
$$

where $t_{n}=\sum_{l=1}^{I} t_{n l} \hat{\pi}_{n l}$ and $t_{n i}$ is an element of $\boldsymbol{t}_{n i}$. McFadden and Train (2000) show that if the coefficients on these artificial variables are jointly insignificant, the null hypothesis that heterogeneity is independently distributed across products cannot be rejected. We calculate artificial variables for border, language, distance and RTA and then estimate:

\section{Equation 12}

$$
\ln \left(\frac{\pi_{n i}}{\pi_{n n}}\right)=S_{i}-S_{n}-\theta \alpha_{i}\left(1-\beta_{i}\right) \boldsymbol{X}_{i} \boldsymbol{\delta}-\theta \boldsymbol{t}_{n i} \boldsymbol{\beta}+\sum_{d=1}^{10}\left(z_{n i_{d}}-z_{n n_{d}}\right) \beta_{d}
$$

where $\boldsymbol{X}_{\boldsymbol{i}}$ and $\boldsymbol{t}_{\boldsymbol{n} i}$ are defined as above and $z_{n i}$ is the artificial variable constructed from the $d^{\text {th }}$ element of the vector of trade cost variables for exporter $i$ in market $n$ and $\beta_{d}$ is the corresponding coefficient. A test of the null hypothesis that the artificial variables are jointly equal to zero is firmly rejected at any reasonable level of significance with an $F$-statistic equal to 8.62 . 


\section{Econometric Results}

\section{Land Productivity Distribution}

Table 2 presents estimates for the land productivity distribution parameters $\boldsymbol{\delta}, \boldsymbol{\Lambda}$, and $\boldsymbol{\Sigma}_{\boldsymbol{E}}$. The total effect of each exporter characteristic in $\boldsymbol{X}_{i}$ on $\pi_{n i}(j)$ is the sum of the mean effect in the first column and the product-specific effects in the columns that follow.

\section{Table 2: Land Productivity Distribution Parameter Estimates}

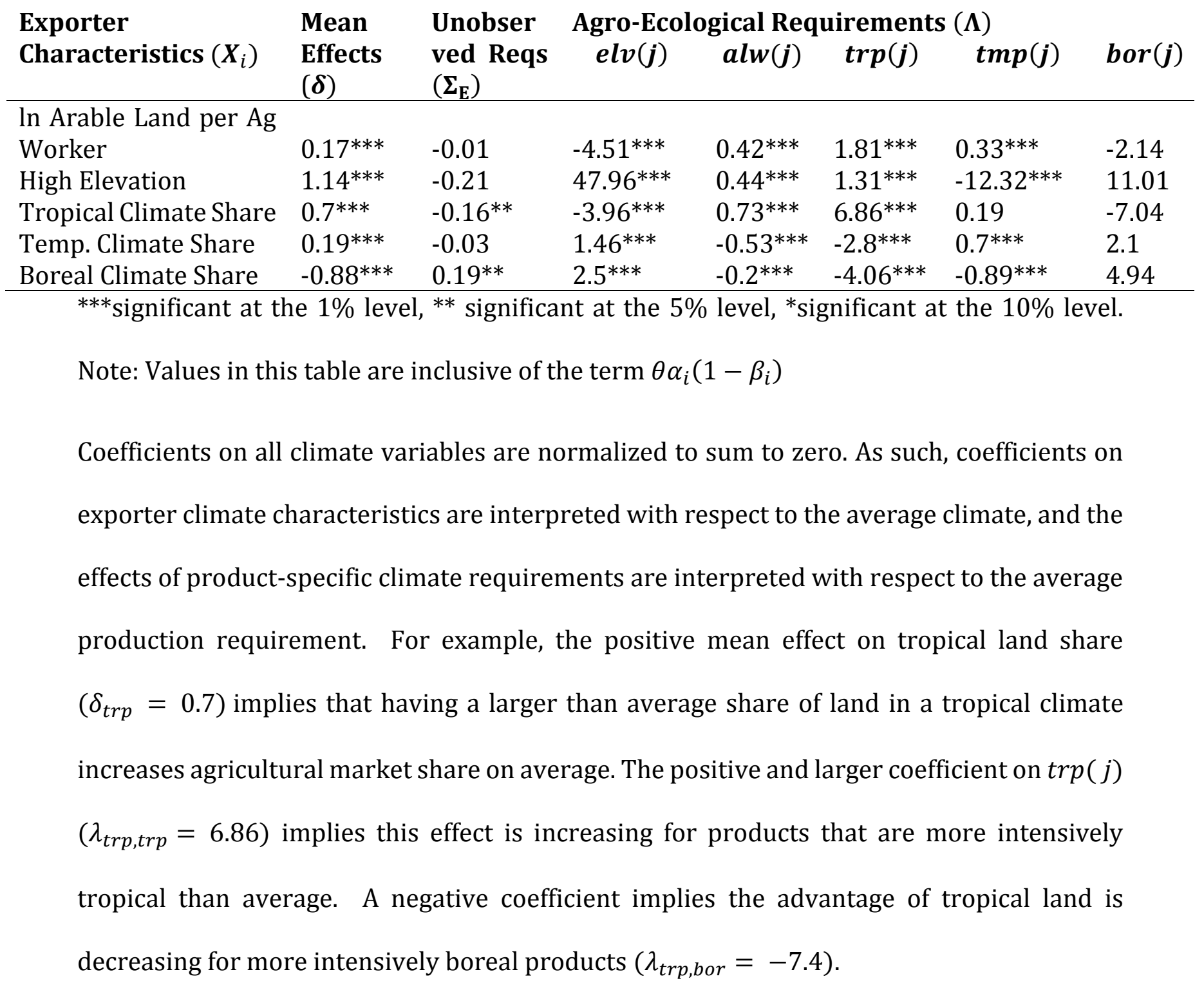


Figure 1 illustrates the distribution of the total effect of high elevation land across the products in our constructed data set. High elevation land decreases the probability of having the lowest price for some products, but raises it for most. The positive mean effect on elevation $\left(\delta_{\text {elev }}=1.14\right)$ implies that having more land at high elevation increases agricultural market share on average. This advantage is greatly magnified for products intensively produced at high elevations $(e l v(j)=47.96)$ and products that are more intensely boreal than the average product $\left(\lambda_{\text {elev,bor }}=11.01\right)$. It is diminished for products more intensively produced in temperate climates than the average product $\left(\lambda_{\text {elev,tmp }}=\right.$ -12.32). The statistically and economically insignificant value of the estimated coefficient on unobservable differences in the effect of high elevation $\left(\sigma_{\text {elev }}=-0.21\right)$, implies that variation in the effect is sufficiently explained by the product requirements in $\boldsymbol{E}(j)$.

\section{Figure 1. Frequency plot - High elevation land effect}

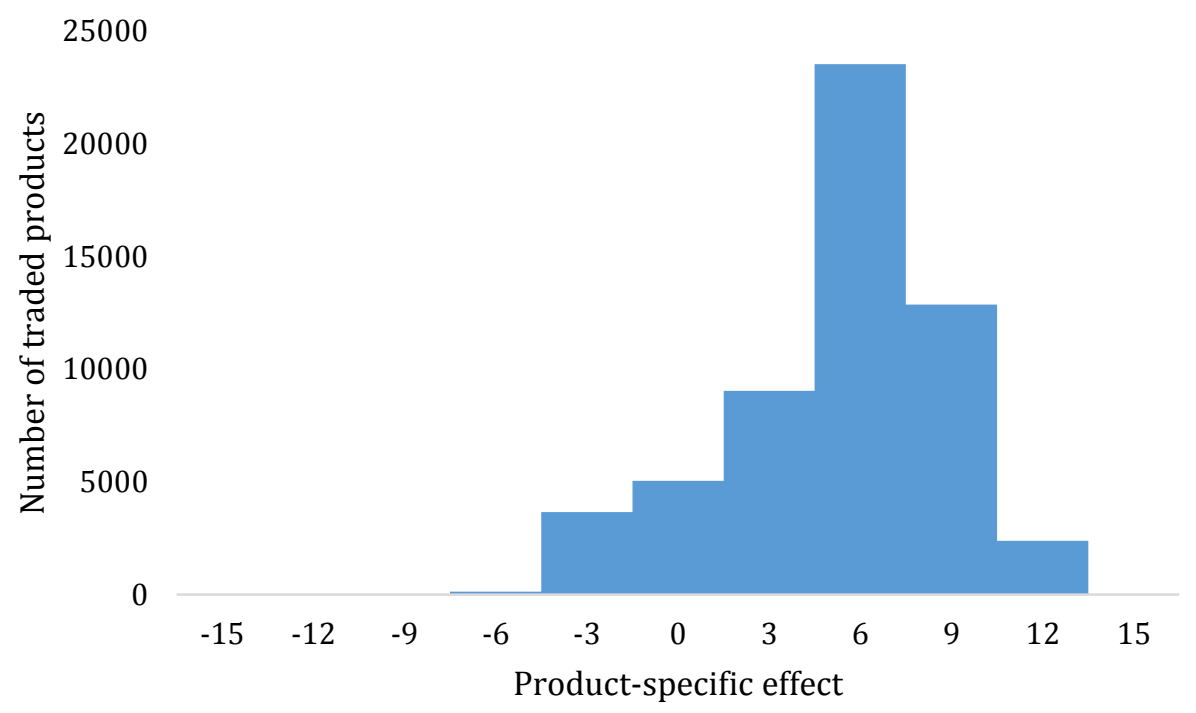

Estimates for $\hat{\tilde{S}}_{i}$ are listed in Table 7 in the Appendix. These values are normalized to sum to zero and are thus interpreted as average sector-level productivity relative to the average 
country, and in the average product. Recall that $\hat{\tilde{S}}_{i}$ is increasing in average technological and land productivity, but decreasing in costs of production $c_{i}$. A country with high average productivity may nevertheless have a small $\hat{S}_{i}$ if it has, e.g., very high wages or land rental rates.

\section{Trade Costs}

Table 3 contains estimates for the trade cost distribution parameters $\boldsymbol{\beta}$ and $\boldsymbol{\Sigma}_{\boldsymbol{t}}$. Positive coefficient values in $\boldsymbol{\beta}$ imply higher trade costs, but lower expected market share. Elements of $\boldsymbol{\Sigma}_{\boldsymbol{t}}$ capture heterogeneity in the effect of each element of $\boldsymbol{t}_{n i}$ across agricultural products and can be interpreted like a standard error around the mean effect.

exporters.

\section{Table 3: Trade Cost Distribution Parameters}

\begin{tabular}{lcl}
$\begin{array}{l}\text { Country Pair } \\
\text { Characteristics }\end{array}$ & $\begin{array}{l}\text { Mean } \\
\text { Effect }\left(\boldsymbol{\beta}^{\boldsymbol{A}}\right)\end{array}$ & $\begin{array}{l}\text { Unobserved } \\
\text { Heterogeneity }\left(\boldsymbol{\Sigma}_{t}\right)\end{array}$ \\
\hline Common Border & $-1.76^{* * *}$ & $3.13^{* * *}$ \\
Common Language & $1.24^{* * *}$ & $0.95^{* * *}$ \\
Common RTA & $0.19^{* *}$ & -0.11 \\
Distance 1 & $-5.28^{* * *}$ & $2.36^{* * *}$ \\
Distance 2 & $-7.67^{* * *}$ & $2.33^{* * *}$ \\
Distance 3 & $-7.43^{* * *}$ & -0.16 \\
Distance 4 & $-9.95^{* * *}$ & $1.37^{* * *}$ \\
Distance 5 & $-11.56^{* * *}$ & -0.04 \\
Distance 6 & $-12.94^{* * *}$ & $0.64^{* * *}$ \\
*** significant at 1\%, ${ }^{* *}$ significant at $5 \%,{ }^{*}$ significant at 10\%.
\end{tabular}

Note: Values in this table are inclusive of the term $\theta$.

In the agricultural sector, positive mean effects imply that sharing a common language and participating in an RTA increase market share on average, while negative coefficients imply 
distance tends to decrease it. The negative mean effect of sharing a border $\left(\beta_{b}=-1.76\right)$ is counterintuitive. However, the relatively larger magnitude of the estimated standard error $\left(\sigma_{b}=3.13\right)$ implies sharing a border increases market share for some products and decreases it for others. Sharing a border may reduce trade in individual products for a number of reasons. For example, domestic agricultural policies often systematically advantage domestic producers relative to their close competitors.

Values of $\widehat{e x}_{i}$ are reported in Table 7 in the Appendix. The values are normalized to sum to zero, so positive (negative) values imply that exporter $i$ is a lower (higher)-than-averagecost exporter. Our results suggest that Belgium, Canada and the United States are the lowestcost exporters in our data set.

\section{Total Bilateral Trade Cost Distribution}

As in a standard gravity model, bilateral trade costs vary across exporters depending upon the characteristics in Table 3. In the SH gravity model, heterogeneity in the effect of these characteristics captures additional variation across products. In Figure 2 we illustrate the distribution of trade costs faced by two high income countries in the U.S. market. The figure confirms that on average, Japanese products face higher costs to enter the U.S. market than Canadian products. In addition to a difference in the location of the distribution, which can be captured in a standard gravity model, higher moments of the distribution appear markedly different. For Canada, trade costs are low on most products, but a few face very high costs to enter the U.S. market. In contrast, trade costs facing Japanese imports are distributed tightly around the median. This can be traced to the relatively large values for the standard deviation around common border $\left(\sigma_{b}=3.13\right)$ and the closest distance 
categories $\left(\sigma_{1}=2.36, \sigma_{2}=2.33\right)$. Differences in the distribution across products are explained in part by differences in options for modes of transport from near versus far, but also on regulatory and other policies that affect bilateral trade asymmetrically across products and countries.

\section{Figure 2. Frequency plot of trade costs faced in U.S. market}
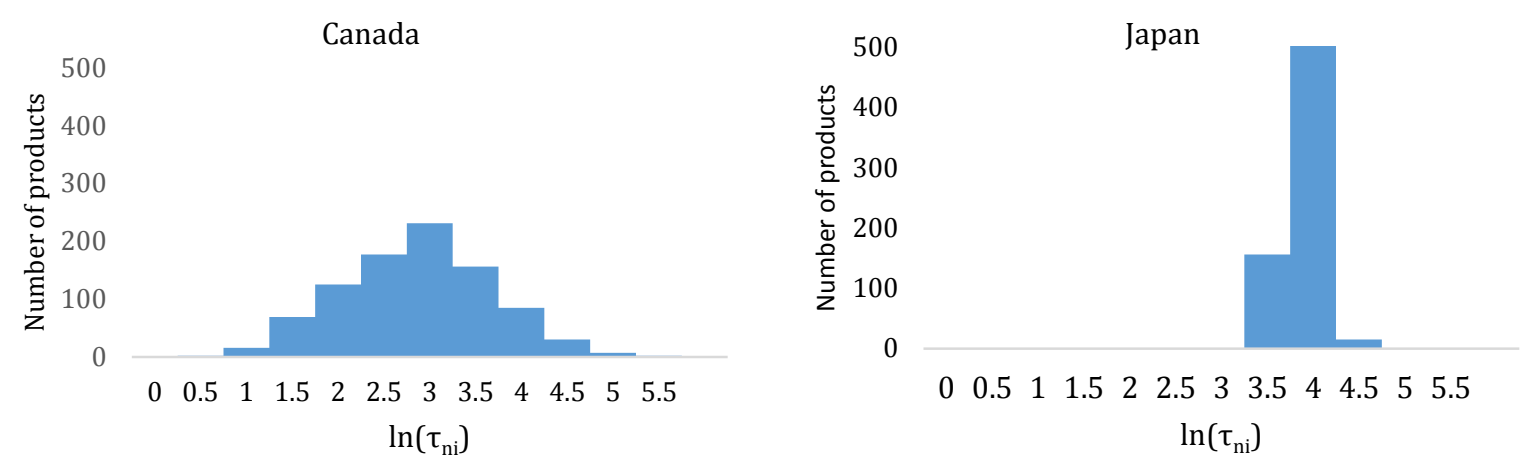

\section{Elasticities}

Parameter estimates in Table 2 and Table 3 allow us to calculate predicted market share (Equation 9) and elasticities using the formulas underlying Equation $4 .^{1}$ To see how the SH gravity model overcomes the limitations of imposing the IIE property highlighted in Arkolakis et al. (2012), we first show that the predicted elasticities are not a constant proportion of market share, as the standard model predicts (Equation 5 ).

We calculate the ratio of the elasticity to Mexican trade costs to market share in Canada, that is $\frac{\partial \pi_{n i}}{\partial \tau_{n l}} \frac{\tau_{n l}}{\pi_{n i}} / \pi_{n l}$, where $l=$ Mexico, $i \neq$ Mexico and $n=$ Canada. Since the relevant elasticity is a

$1 \frac{\partial \pi_{n i}}{\partial \tau_{n l}} \frac{\tau_{n l}}{\pi_{n i}}=\left\{\begin{array}{cc}-\frac{\theta}{\pi_{n i}} \int \pi_{n i}(j)\left(1-\pi_{n i}(j)\right) d F_{\tilde{a}}(\widetilde{\boldsymbol{a}}) d F_{\tau_{n}}(\boldsymbol{\tau}) & \text { if } l=i \\ \frac{\theta}{\pi_{n i}} \int \pi_{n i}(j) \pi_{n l}(j) d F_{\tilde{a}}(\widetilde{\boldsymbol{a}}) d F_{\tau_{n}}(\boldsymbol{\tau}) & \text { otherwise }\end{array}\right.$ Integrals are simulated as in Equation 9. 
direct elasticity for $i=$ Mexico, we divide Mexico's own elasticity by $\left(1-\pi_{\text {CanMex }}\right)$. This ratio would be the same (equal to $\theta$ ) for every country in the standard model. In the SH model the ratio varies dramatically depending on characteristics of the exporter and the products they export to Canada. Table 4 reports this ratio for the countries with the largest share of Canadian expenditure on the products in our data set. The SH gravity model predicts that Colombia, Chile and Indonesia would gain disproportionately from higher Mexican trade costs, whereas gains in Canadian and U.S. market share will be proportionately smaller.

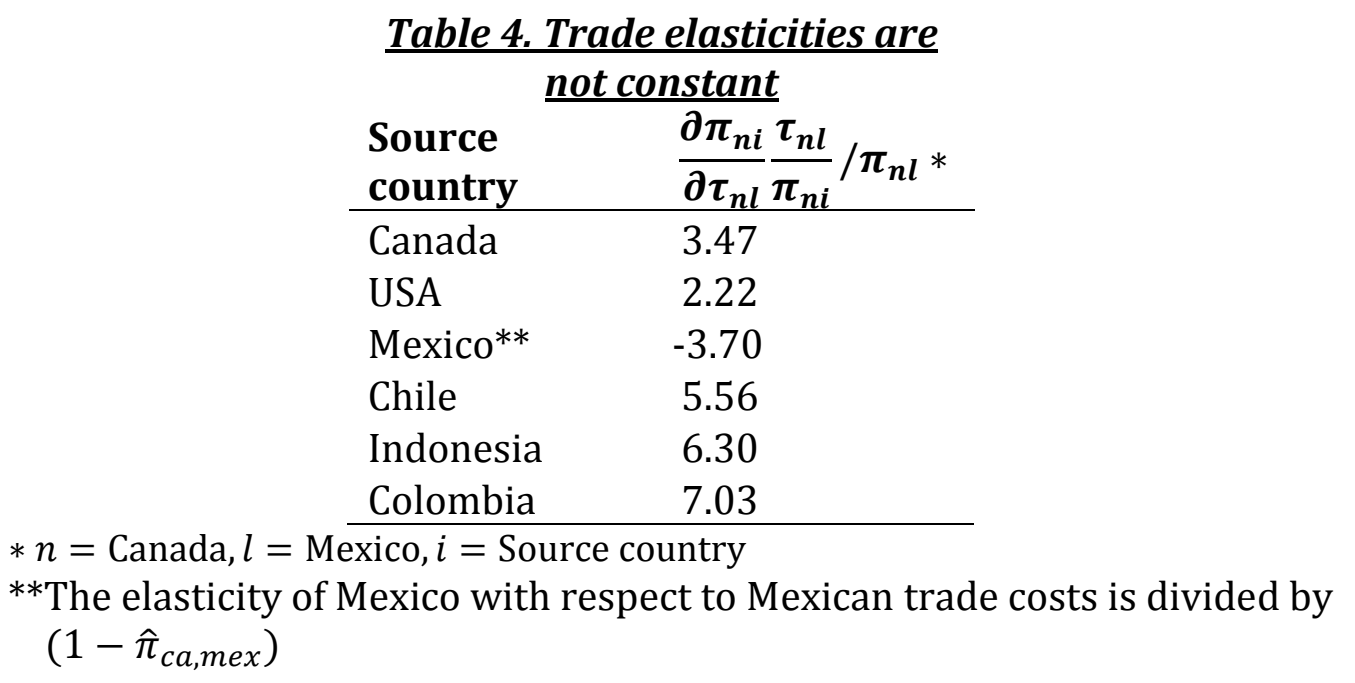

As discussed earlier in this paper, Arkolakis et al. (2012) highlight two consequences of these restrictive elasticities implied by the IIE property. First, an increase in $\tau_{n i}$ has a symmetric effect on relative expenditure $\left(X_{n i} / X_{n n}\right)$ for all countries regardless of the characteristics of markets for the agricultural products they export. To illustrate how the $\mathrm{SH}$ gravity model overcomes this restriction, we calculate the elasticity of $\pi_{n i}$ with respect to $\tau_{n i}$ for each country $i$ and $n=$ Canada, and use it to calculate new values for relative market share, $\pi_{n i}^{\prime} / \pi_{n n}{ }^{\prime}$. Although relative expenditure and relative market share are equivalent by definition, we present our results in terms of market share since it is the object we calculate. 
Table 5 presents the ratio $\frac{\pi_{n i}^{\prime}}{\pi_{n n}^{\prime}} / \frac{\pi_{n i}}{\pi_{n n}}$ for the foreign countries with the largest share of Canadian expenditure in our data set. Again, whereas this value would be identical for every country in the standard model, the SH model allows the response of relative demand to changes in countries' own trade costs to vary. Interestingly, the SH model finds that relative market share generally declines less for countries with a larger initial share of the Canadian market than for the median exporter. However, the value of the ratio does not decline monotonically with market share. For example, a larger ratio (0.963 versus 0.960$)$ suggests that Indonesian exports face less head-to-head competition in the Canadian market than do those of Chile, which represent a larger share of Canadian expenditure in the base model. A particularly small decline suggests that U.S. exporters generally face less intense price competition in the Canadian market. This is a substantial advantage, likely due to geographical and cultural proximity as well as trade preferences.

\section{Table 5. Changing trade costs do not have symmetric effects on relative demand}

\begin{tabular}{ll} 
Country & $\frac{\boldsymbol{\pi}_{\boldsymbol{n} \boldsymbol{i}}^{\prime}}{\boldsymbol{\pi}_{\boldsymbol{n} \boldsymbol{n}}^{\prime}} / \frac{\boldsymbol{\pi}_{\boldsymbol{n} \boldsymbol{i}} *}{\boldsymbol{\pi}_{\boldsymbol{n} \boldsymbol{n}}}$ \\
\hline USA & 0.980 \\
Mexico & 0.963 \\
Chile & 0.960 \\
Indonesia & 0.963 \\
Colombia & 0.961 \\
Costa Rica & 0.963 \\
Median & 0.959 \\
\hline \multicolumn{2}{l}{$*$ Canada, $i=$ Source country }
\end{tabular}

The second consequence discussed in Arkolakis et al. (2012) is that relative market share is unaffected by a change in a third country's trade costs. This is essentially a statement of the 
IIE assumption and a straightforward parallel to the "red bus-blue bus problem" referenced extensively in the literature on discrete choice demand systems. ${ }^{2}$ The standard gravity model predicts that higher trade costs will drive Canadian buyers to substitute away from Mexican products and toward all other sources proportionately such that $\frac{\pi_{n i}}{\pi_{n n}}(i \neq$ Mexico $)$ is unchanged, regardless of whether country $i$ is likely to specialize in products that are substitutable for those Mexico exports to Canada. To explore the extent to which the SH model overcomes this restriction we use the elasticities with respect to Mexican trade costs in the Canadian market from Table 4 to calculate predicted new values for relative market share: $\pi_{n i}^{\prime \prime} / \pi_{n n}^{\prime \prime}$. Table 6 presents the ratio $\frac{\pi_{n i}^{\prime \prime}}{\pi_{n n}^{\prime \prime}} / \frac{\pi_{n i}}{\pi_{n n}}$ for the countries with the largest and smallest values.

\section{Table 6. Changing third country trade costs do not have a proportional impact on relative market share}

\begin{tabular}{ll} 
Source & $\pi_{n i}{ }^{\prime \prime}$ \\
Country & $\frac{\pi_{n i}}{\pi_{n n}{ }^{\prime \prime}} / \frac{\pi_{n n}}{\pi_{n}}$ \\
\hline Costa Rica & 1.0043 \\
Honduras & 1.0041 \\
Venezuela & 1.0041 \\
Australia & 1.0000 \\
Kazakhstan & 0.9999 \\
USA & 0.9997 \\
Median & 1.0000 \\
\hline$n=$ Canada, $i=$ Source country
\end{tabular}

Whereas the value of this ratio would be exactly equal to one for every country in the standard gravity model, the SH model picks up variation, albeit small - the relative market

\footnotetext{
2 Train (2009) describes this famous problem of modeling consumer choice between traveling to work by blue bus or by car. In a model that assumes the IIA, the introduction of a new red bus that is otherwise equivalent to the blue bus will predict that consumers substitute toward the red bus in proportion to their use of the blue bus and car.
} 
share of the most responsive country increases by only 0.4 percent more than the least responsive. $^{3}$ However, the variation in elasticities is in the direction we expect: The SH model predicts that Mexico's neighbors with similar climates - Costa Rica and Honduras gain proportionately more from Mexico's lost access. Larger changes in trade costs and changes in the dispersion of trade costs can translate into more substantial differences in predicted trade flows.

\section{Conclusions}

In this paper we have detailed two disadvantages of the standard gravity model for applied analysis of agricultural trade and presented a tractable alternative, the SH gravity model. We have shown that the SH gravity model can overcome the limitations on bilateral trade elasticities embodied by the IIE property. We discuss the work of Arkolakis et al. (2012), who explain that it is the assumption of a CES import demand system that delivers a gravitylike structural relationship in the most common trade models, but also imposes the IIE property. The SH gravity model loosens the CES import demand system assumption while maintaining a gravity-like structural relationship. The model is specified as a randomcoefficients logit model (Berry et al., 1995). Using interactions between exporter land and climate characteristics and product land and climate production requirements, it identifies countries likely to have comparative advantage in similar products. These countries' trade flows are then more elastic to each other's trade costs.

\footnotetext{
${ }^{3}$ Values less than one imply that domestic (Canadian) producers gain proportionately more market share than the United States and Kazakhstan.
} 
We have also shown how the SH gravity model can accommodate product-specific trade costs. This allows the model to analyze changes in the dispersion of trade costs across products. Such analysis cannot be carried out in a standard gravity model, in which trade costs are assumed constant. Our results confirm economically and statistically significant heterogeneity in the effects of the variables that typically proxy for trade costs in gravity models.

In our ongoing work developing the SH gravity model, we seek to improve the model and its general equilibrium extension on several fronts, with an explicit objective of enhancing its usefulness for applied analysis of agricultural trade policy. First, in addition to updating the trade and production data, we are exploring alternative approaches to constructing the distribution of products consumed. Currently, we assume that the distribution of products consumed is adequately represented by the distribution of imported products. However, if high product-specific tariffs sufficiently limit imports of a given product, it will be underrepresented and the estimates of gains from reducing those tariffs will be under-estimated.

Second, we are gathering data and adapting the estimation methodology in order to introduce observable sources of trade cost heterogeneity arising from policy differences like tariffs and non-tariff measures, as well as from intrinsic characteristics like perishability. Finally, we are pursuing methodological changes to improve product and sub-sector level analysis within the model, allowing for a better understanding of the distributional consequences of changes in trade costs. 


\section{References}

Adao, R., Costinot, A., Donaldson, D. 2017. Nonparametric counterfactual predictions in neoclassical models of international trade. American Economic Review 107(3), 633-689.

Anderson, J.E., van Wincoop, E., 2003.Gravity with gravitas: a solution to the border puzzle. American Economic Review 93 (1), 170-192.

Anderson, J.E., van Wincoop, E., 2004. Trade costs. Journal of Economic Literature 42 (3), 691751.

Anderson, J.E., Yotov, Y.V. 2010a. The changing incidence of geography. American Economic Review 100 (5), 2157-2186.

Anderson, J.E., Yotov, Y.V. 2010b. Specialization: Pro-and anti-globalizing, 1990-2002. NBER Working Paper 16301. NBER, Cambridge, MA.

Anderson, J.E., Yotov, Y.V. 2012. Gold standard gravity. NBER Working Paper 17835. NBER, Cambridge, MA.

Arkolakis, C., Costinot, A., Rodríguez-Clare, A. 2012. New trade models, same old gains? American Economic Review 102(1), 94-130.

Bagwell, K., Bown, C.P., Staiger, R.W. 2016. Is the WTO passé? Journal of Economic Literature 54(4), 1125-1231.

Berry, S. 1994. Estimating discrete-choice models of product differentiation. RAND Journal of Economics 25(2), 242-262.

Berry, S., Levinsohn, J, Pakes, A. 1995. Automobile prices in market equilibrium. Econometrica 63(4), 841-890.

Burfisher, M.E., Dyck, J., Meade B., Mitchell, L, Wainio, J. Zahnhiser, S., Arita, S., Beckmann, J. 2014. Agriculture in the Trans-Pacific Partnership. Economic Research Report Number 176. Economic Research Service, United States Department of Agriculture, Washington DC.

Burstein, A., Vogel, J. 2010. Globalization, technology, and the skill premium: A quantitative analysis. NBER Working Paper 16459. NBER, Cambridge MA.

Caliendo, L., Parro, F. 2015. Estimates of the trade and welfare effects of NAFTA. Review of Economic Studies 82 (1), 1-44.

Cardamone, P. 2011. The effect of preferential trade agreements on monthly fruit exports to the European Union. European Review of Agricultural Economics 38(4), 553-586.

Chaney, T., 2008. Distorted gravity: The intensive and extensive margins of international trade. American Economic Review 98(4), 1707-1721.

Chevassus-Lozza, E., Latouche, K. 2012. Firms, markets and trade costs: access of French exporters to European agri-food markets. European Review of Agricultural Economics $39(2), 257-288$. 
Chor, D. 2010. Unpacking sources of comparative advantage: A quantitative approach. Journal of International Economics 82(2), 152-167.

Center for International Earth Science Information Network (CIESIN). 2010. National Aggregates of Geospatial Data Collection: Population, Landscape and Climate Estimates. CIESIN, Columbia University, NY.

Costinot, A., Donaldson, D., Komunjer, I. 2012. What goods do countries trade? A quantitative exploration of Ricardo's ideas. Review of Economic Studies 79(2), 581-608.

Costinot, A., Rodríguez-Clare, A. 2014. Trade theory with numbers: Quantifying the consequences of globalization in G. Gopinath, E. Helpman, and K. Rogoff, eds. Handbook of International Economics. North-Holland, Amsterdam.

Dal Bianco, A., Boatto, V.L., Caracciolo, F., Santeramo, F.G., 2016. Tariffs and non-tariff frictions in the world wine trade. European Review of Agricultural Economics 43(1), 3157.

Eaton, J., Kortum, S., 2002. Technology, geography, and trade. Econometrica 70 (5), 17411779.

Fally, T., Sayre, J. 2018. Commodity trade matters. Unpublished manuscript. UC Berkeley.

Feenstra, R.C., 2004. Advanced International Trade: Theory and Evidence. Princeton University Press, Princeton, NJ.

Food and Agricultural Organization of the United Nations (FAO). 2013. FAOSTAT Database. FAO, Rome.

Greene, W. 2003. Econometric Analysis, $5^{\text {th }}$ ed, Prentice Hall, Upper Saddle River, NJ.

Head, K., Mayer, T., 2014. Gravity equations: workhorse, toolkit, and cookbook in G. Gopinath, E. Helpman, and K. Rogoff, eds. Handbook of International Economics. NorthHolland, Amsterdam.

Head, K, Mayer, T., Ries. 2009. How remote is the offshoring threat? European Economic Review 53(4), 429-444.

Heerman, K, E.R. 2013. Technology, ecology and agricultural trade. PhD dissertation, University of Minnesota.

Heerman, K.E.R., Arita, S., Gopinath, M. 2015. Asia-Pacific integration with China versus the United States: Examining trade patterns under heterogeneous agricultural sectors. American Journal of Agricultural Economics 97(5), 1324-1344.

Jales, M., Josling, T., Nassar, A., Tutwiler, A. 2005. Options for agriculture: From framework to modalities in market access/domestic support/export competition. Trade Policy Issues Paper No. 2. International Agricultural Trade Research Consortium (IATRC), Minneapolis St.Paul, MI. 
Jayasinghe, S., Beghin, J.C., Moschini, G. 2009. Determinants of world demand for U.S. corn seeds: The role of trade costs. American Journal of Agricultural Economics 92(4), 9991010.

Kerr, W.R. 2017. Heterogeneous technology diffusion and Ricardian trade patterns. The World Bank Economic Review, 1-20, doi: 10.1093/wber/lhx002.

Lee, H-L, Hertel, T., Sohngen, B., Ramankutty, N. 2005. Towards and integrated land use data base for assessing the potential for greenhouse gas mitigation. GTAP Technical Paper No. 25. Center for Global Trade Analysis (GTAP), Department of Agricultural Economics, Purdue University, West Lafayette, IN.

McFadden, D., Train, K. 2000. Mixed MNL models for discrete response. Journal of Applied Econometrics 15(5), 447-470.

Melitz, M.J., 2003. The impact of trade on intra-industry allocations and aggregate industry productivity. Econometrica 71 (6), 1695-1725.

Nevo, A. 2000. A practitioner's guide to estimation of random-coefficients logit models of demand. Journal of Economics and Management Strategy 9(4), 513-548.

Reimer, J. J., Li, M. 2010. Trade costs and the gains from trade in crop agriculture. American Journal of Agricultural Economics 92 (4), 1024-1039.

Shiker, S. 2011. Capital, technology, and specialization in the neoclassical model. Journal of International Economics 83(2), 229-242.

Shiker, S. 2012. Predicting the effects of NAFTA: Now we can do it better! Journal of International and Global Economic Studies 5(2), 32-59.

Simonovska, I., Waugh, M.E. 2014. The elasticity of trade: Estimates and evidence. Journal of International Economics 92 (1), 34-50.

Tombe, T. 2015. The missing food problem: Trade, agriculture, and international productivity differences. American Economic Journal: Macroeconomics 7(3), 226-258.

Train, K. 2009. Discrete Choice Methods with Simulation. Cambridge University Press, Cambridge, MA.

World Bank. 2012. World Development Indicators. World Bank, Washington DC.

$\mathrm{Xu}, \mathrm{K} .2015$. Why are agricultural goods not traded more intensively: High trade costs or low productivity variation? World Economy 38 (11), 1722-1743. 


\section{Appendix}

Table 7: Average Productivity and Exporter Cost Estimates

\begin{tabular}{lll} 
Country & \multicolumn{1}{c}{$\widehat{\widetilde{\boldsymbol{S}}}_{\boldsymbol{i}}$} & \multicolumn{1}{c}{$\widehat{\boldsymbol{e x}}_{\boldsymbol{i}} / \boldsymbol{\theta}$} \\
\hline Argentina & $0.86^{* * *}$ & $1.17^{* * *}$ \\
Australia & $0.85^{* * *}$ & $0.3^{* * *}$ \\
Austria & $-1.06^{* * *}$ & -0.03 \\
Belgium & $-8.3^{* * *}$ & $2.96^{* * *}$ \\
Bolivia & 0.34 & $-1.54^{* * *}$ \\
Brazil & $0.7^{* * *}$ & $0.69^{* * *}$ \\
Bulgaria & $0.08^{* * *}$ & $-0.11^{* * *}$ \\
Canada & $-5.75^{* * *}$ & $2.79^{* * *}$ \\
Chile & $1.66^{* * *}$ & $1.21^{* * *}$ \\
China & $2.61^{* * *}$ & 1.16 \\
Colombia & $1.42^{* * *}$ & $0 * * *$ \\
Costa Rica & $1.15^{* * *}$ & $-0.81^{* * *}$ \\
Cote d'Ivoire & 0.56 & $-0.75^{* * *}$ \\
Czech Republic & $0 * *$ & -0.48 \\
Denmark & $0.44^{* * *}$ & $0.04^{* * *}$ \\
Ecuador & $1.21^{* * *}$ & $-0.32^{* * *}$ \\
Estonia & 2.77 & $-2.56^{* * *}$ \\
Ethiopia & $-0.37^{* * *}$ & $-0.96^{* * *}$ \\
Finland & $1.72^{* * *}$ & $-1.58^{* * *}$ \\
France & $-2.96^{* * *}$ & $1.76^{* * *}$ \\
Germany & -4.87 & $2.41^{* * *}$ \\
Ghana & $-0.35^{* * *}$ & -1.06 \\
Greece & 1 & $0.1^{* * *}$ \\
Honduras & $-0.24^{* * *}$ & $-1.35^{* * *}$ \\
Hungary & 2.1 & $-0.67^{* * *}$ \\
Iceland & $-0.14^{* * *}$ & $-2.2^{* * *}$ \\
India & $1.13^{* *}$ & $0.57^{* * *}$ \\
Indonesia & $0.55^{* * *}$ & $0.78^{* * *}$ \\
Ireland & $2.14^{* * *}$ & -1.3 \\
Israel & $1.58^{* * *}$ & $0.06^{* * *}$ \\
Italy & $-3.31^{* * *}$ & $2 * * *$ \\
Japan & $-1.68^{* * *}$ & $0.75^{* * *}$ \\
Kazakhstan & $0.78^{* *}$ & $-1.76^{* * *}$ \\
Lithuania & $-0.51^{* * *}$ & $-0.7^{* * *}$ \\
Malaysia & $-2.74^{* * *}$ & $-2.13^{* * *}$ \\
Mexico & $0.65^{* * *}$ & $1.51^{* * *}$ \\
He.5** \\
\end{tabular}




\begin{tabular}{|c|c|c|}
\hline Country & $\widehat{\widetilde{\boldsymbol{S}}}_{\boldsymbol{i}}$ & $\widehat{e x}_{i} / \theta$ \\
\hline Morocco & $1.41^{* * *}$ & $-0.88^{* * *}$ \\
\hline Netherlands & $-3.12^{* * *}$ & $2.16^{* * *}$ \\
\hline New Zealand & $2.8^{* * *}$ & $0.35^{* * *}$ \\
\hline Norway & $2.41^{* * *}$ & $-2.41^{* * *}$ \\
\hline Paraguay & $1.48^{* * *}$ & -0.67 \\
\hline Peru & 1 & 0.12 \\
\hline Poland & $-0.2^{* * *}$ & $0.03^{* *}$ \\
\hline Portugal & $-1.55^{* * *}$ & $0.17^{* * *}$ \\
\hline Russia & $-2.49 * * *$ & $0.16^{* * *}$ \\
\hline Slovakia & $3.07^{* * *}$ & $-2.15^{* * *}$ \\
\hline Slovenia & 1.63 & $-2.05^{* * *}$ \\
\hline South Africa & $-0.07 * * *$ & $0.41^{* *}$ \\
\hline South Korea & $1.85^{* * *}$ & $-0.21^{* * *}$ \\
\hline Spain & $-3.82^{* * *}$ & 2.12 \\
\hline Sri Lanka & $1.36^{* * *}$ & $0.11^{* * *}$ \\
\hline Sweden & $-0.64^{* * *}$ & $-0.25^{* * *}$ \\
\hline Switzerland & -2.46 & $0.31^{* * *}$ \\
\hline Thailand & $-0.27^{* * *}$ & $0.28^{* * *}$ \\
\hline Tunisia & $3.04^{* * *}$ & $-1.13^{* * *}$ \\
\hline Turkey & $1.32^{* * *}$ & $0.56^{* * *}$ \\
\hline Ukraine & $1.31^{* * *}$ & $-0.5^{* * *}$ \\
\hline UK & $-4.05^{* * *}$ & 2.13 \\
\hline Uruguay & $2.68^{* *}$ & $-0.12^{* * *}$ \\
\hline Venezuela & $0.62^{*}$ & $-2.36^{* * *}$ \\
\hline Vietnam & $0.4^{* * *}$ & $0.35^{* * *}$ \\
\hline USA & $-4.36^{* * *}$ & $3.04^{* * *}$ \\
\hline
\end{tabular}

${ }^{* * *}$ significant at the $1 \%$ level, ${ }^{* *}$ significant at the $5 \%$ level, ${ }^{*}$ significant at the $10 \%$ level. 